\title{
Factors Affecting Performance of Healthcare Workers During COVID-19 in Pakistan
}

\author{
Dr Muhammad Jafar ${ }^{+*}$ and Dr Aisha Shoukat ${ }^{*}$
}

\section{Abstract}

Healthcare workers are one of the most affected communities at the global level during the pandemic of COVID-19, and Pakistan is no exception. Pakistan allocates merely less than $1 \%$ of its GDP for the healthcare sector, that is why, in most of the cases, healthcare workers are bound to serve without adopting standard safety measure while dealing with patients. The need for proper Personal Protection Equipment (PPE) has been felt more than ever during the occurrence of COVID19 due to its quick transferability from an infected person to a healthy one. Until now, some 62 healthcare workers, including 42 doctors, have lost their lives and 5,367 have contracted coronavirus. Healthcare workers already serving without PPEs went under serious life threat after coronavirus pandemic, and this fear has adversely affected their role as frontline warriors against COVID-19. In the given scenario, healthcare workers have not only to be worried about their own lives but also their families back at home. The current study aims at investigating variables such fears of healthcare workers about contracting coronavirus, its adverse effects on their performance and resultantly the provision of compromised healthcare services to patients. This is mainly a qualitative study, whereas primary data were collected through telephonic interviews of 30 healthcare workers (15 doctors and 15 nurses) currently performing their duties in healthcare centres. Sources of secondary data include online journal articles, daily newspapers, government reports and official websites. The findings of the study show that lack of proper safety kits and training of preparedness and safety has put the lives of healthcare workers at high risk and they are unable to perform their duties in the proper/appropriate way owing to their exposure to risk of contracting coronavirus. The healthcare workers are conflicted about serving and saving the patients or securing their own lives.

Keywords: Healthcare Workers; COVID-19; Personal Safety Equipment; Pakistan

\footnotetext{
${ }^{+}$Lecturer, Department of Social Work, The Islamia University of Bahawalpur, Pakistan

${ }^{*}$ Corresponding Author, Email: jaffarwattoo@gmail.com

$¥$ Assistant Professor, Department of Social Work, The Islamic University of Bahawalpur, Pakistan,

Email: aishashah1@yahoo.com

(C) 2020 Jafar \& Shoukat. This is an Open Access article distributed under the terms of the Creative Commons Attribution License (http://creativecommons.org/licenses/by/2.0), which permits unrestricted use, distribution, and reproduction in any medium, provided the original work is properly cited.
} 


\section{Introduction}

The coronavirus pandemic originated from Wuhan city of China on 8 December 2019 and spread speedily at global level affecting 210 countries. However, Pakistan remained safe until 26 February 2020, when the first two coronavirus confirmed cases were reported in Karachi and Islamabad. Both reported cases were pilgrims who had recently travelled from Iran after performing pilgrimage (Emro, 2019).

Pakistan spends less than $1 \%$ of its GDP on healthcare which is quite insufficient for meeting the emerging needs of an ever-growing population (Khalid \& Abbasi, 2018). That is why communicable and non-communicable diseases are increasing in the country, and the healthcare system is deteriorating gradually, making vulnerable populations more prone to health problems (Koo et al., 2020). Due to the overburdening of hospitals, healthcare services are just limited to curative measures and not prevention. In developing countries like Pakistan, the imposition of complete lockdown and social distancing is not possible due to economic reasons. Preparedness and response of the country to pandemics like coronavirus is critical for disease surveillance, diagnostics workup, clinical management, prevention and control of infection, and risk communication. However, the healthcare system of Pakistan was not prepared to respond to such a big challenge (Sherin, 2020).

Healthcare workers on the front line are forced to deal with contagious diseases like coronavirus pandemic; this makes healthcare workers at a high risk of getting a disease (Rosenbaum, 2020). The coronavirus outbreak has deeply influenced the healthcare system of both developed and developing countries. In South Asian countries like Pakistan, Bangladesh, and India, the healthcare system is not efficient and adequate, like in Europe, UK and USA (Deshwal, 2020).

In Pakistan, both public and private sectors failed to provide critical medical care to coronavirus infected persons who needed ICU services, including ventilators. The outbreak of coronavirus has brought several unprecedented challenges which were not seen in recent human history. Coronavirus patients may suffer from milder illness and recovery to acute illness resulting in death. On 31 December 2020, the World Health Organization (WHO) was alerted to pneumonia cases in China. As a result, on 30 January, WHO declared it as a public health emergency based on its high-risk assessment (Waris et al., 2020). As mentioned earlier, the first case of coronavirus in Pakistan was reported in the last week of February 2020 (Saqlain et al., 2020), and as a precautionary measure, the government closed all educational institutions two weeks later on 13 March. By that time, when there was a significant increase in coronavirusinfected persons, all the provincial governments announced lockdown for initially two weeks. During the lockdown, air, rail, and road services were suspended except for unavoidable reasons. Likewise, all the shops, shopping malls, and business activities were halted except for grocery stores, milk shops, and cylindrical clay ovens (Zia \& Farooq, 2020).

Since the existence of Pakistan, successive governments have taken specific concrete steps for up-gradation and revamping of public sector hospitals. However, all such efforts were limited in scope and could not build the healthcare system of Pakistan to manage such a vast population (Kurji et al., 2016).

The healthcare system of Pakistan has several flaws such as poor governance, lack of adequate resources for purchasing modern medical apparatus, corruption and embezzlement of funds, poor planning and coordination, and inadequate systems for monitoring implementation of health policies along with lack of professionalism and proper training of medical and paramedical staff (Koo et al., 2020). All these factors have collectively made the healthcare system a poor one which is unable to deliver on equal basis to the rich and poor. There is a wider gap between access of healthcare services by two main strata of Pakistani society; haves and have nots (Kurji et al., 2016). Healthcare services are lacking in rural areas of 
Pakistan because of poor infrastructure of Basic Health Units (BHU) and Rural Health Centres (RHC), that is why people in need of medical attention do not visit these centres. People always travel to big cities where there are tertiary care hospitals, relatively better equipped with qualified doctors and medical apparatus. However, due to physical distance, the majority of the population fails to utilise these medical services (Khan \& Van den Heuvel, 2007). According to the Ministry of National Health Service Regulations and Coordination, Government of Pakistan (2019), the healthcare system of Pakistan has the following three tiers.

\section{Primary Healthcare}

Primary healthcare tier is comprised of BHUs and RHCs. BHUs are located at union council level and serve a population up to 25,000 individuals. The services being rendered at these units include preventive, curative, and referral. Similarly, provision of Maternal and Child Health (MCH) services are also part of BHUs. Additionally, BHUs provide clinical, logistic, and managerial services to Lady Health Workers (LHWS) who cover assigned areas through using this platform. Rural Health Centres (RHCs) cover a catchment population of up to 100,000 individuals. RHCs provide promotive, preventive, diagnostic, and referral services, along with inpatient services. Just like BHUs, RHCs also provide clinical, logistic, and managerial support to LHWs and $\mathrm{MCH}$ centres falling in their respective jurisdiction.

\section{Secondary Healthcare}

The secondary healthcare tier consists of Tehsil Head Quarters (THQs) and District Head Quarters (DHQs) hospitals. A THQ serves a population of 0.5 to 1 million people whereas a DHQ covers a population of 1-3 million. A THQ deals with the basic and comprehensive emergency, obstetrics, and new born care, along with handling referred cases from BHUs and RHCs. Similarly, DHQs are located at the district level and provide comprehensive healthcare services including promotive, preventive, curative, diagnostics, inpatient, and referral services

\section{Tertiary Healthcare}

Tertiary care hospitals are for more specialised indoor and outdoor patients. Tertiary care hospitals are attached to teaching hospitals and are located at the divisional level except for in metropolitan cities. Tertiary care hospitals are equipped with all kinds of medical apparatus and specialisation and provide comprehensive healthcare services to a range of patients.

\section{Preparedness of Healthcare System in Response to Coronavirus}

Currently, Pakistan is the fifth most populous country in the world with a population of 220 million. Researchers such as Zia and Farooq (2020) maintained that following four factors make the Pakistani population vulnerable to pandemics like coronavirus; the colossal volume of population, insufficient and inadequate infrastructure, massive poverty and typical (rigid) culture (Zia \& Farooq, 2020). During the coronavirus outbreak, Pakistani hospitals were facing an acute shortage of high dependency units, well-equipped ICUs, and ventilators for meeting the medical needs of critical coronavirus infected patients. Similarly, there was also a dearth of intensivists and trained staff for operating ventilators. In this situation, it can be stated that healthcare workers are fighting with coronavirus infection 'unarmed.' According to WHO guidelines, healthcare workers must be fully equipped with proper PPE including medical and surgical masks, face shields, goggles, gloves, full gowns, long shoes, and sanitisers (World Health Organization, 2020).

The representative of Pakistan Medical Association (PMA) highlighted sufferings of healthcare workers in these words "politicians and bureaucrats are often seen wearing $\mathrm{N}-95$ masks during meetings and visits... healthcare professionals are facing a dire shortage of fthese masks) and PPE." During the coronavirus outbreak, healthcare workers in one city were also beaten by police with sticks and fists for demanding PPEs and other necessary equipment needed for treatment of critical patients (Khan, 2020). During the coronavirus outbreak, it was not only masses at the risk of contraction with the deadly virus but also healthcare workers, 
including doctors, nurses, and paramedical staff because of unavailability of proper PPE. Because healthcare workers were the frontline force for fighting against this pandemic, the number of healthcare workers infected with coronavirus were putting their own as well as their families' lives at high risk (Salman et al., 2020).

Pakistan is already a resource-poor country, and could not provide safety kits to healthcare workers, especially those serving in small cities and rural areas. They are exposed to a wide range of infection risks, including coronavirus. The bleeding healthcare system of Pakistan is unable to appropriately respond to epidemics like Hepatitis and Dengue fever, as well as other such seasonal health problems. Now, during the coronavirus outbreak, it is obvious that decades of the negligence of the healthcare sector has been exposed and hospitals are unable to accommodate all the coronavirus infected patients, whilst other general patients have been denied medical attention except emergency. The coronavirus pandemic has revealed that the successive governments have neglected the healthcare infrastructure and its implications are open to everyone.

The study aims at exploring different factors affecting the performance of healthcare workers during COVID-19 in Pakistan. The paper has been divided into four main sections. The first section encapsulates introduction. The second section is comprised of the literature review and methodology; section three is based on the findings of the study. Last section four contains discussions and conclusion.

\section{Review of Literature}

In the wake of Eid ul Fitar, which is one of most celebrated religious festivals in Pakistan, the government eased lockdown and permitted the opening of shops and markets with strict compliance to Standard Operating Procedures (SOPs) However, careless citizenry in Pakistan grossly violated all safety measures including social distancing, wearing masks, and use of hand sanitisation, which resulted into the exponential growth of coronavirus infected persons and death ratio in the country. This increasing number of coronavirus patients put pressure on hospitals and healthcare workers (Tribune, 2020).

Coronavirus brought fear and stress with it because of its quick transformation pattern from one person to another. There were uncertainty and unpredictability about the pandemic in term of clinical presentation, epidemiological characteristics, novelty, implications for national and international public health, and lack of preparations for responding to this deadly virus. Because of its coverage in electronic, print, and social media at the national and international level, coronavirus created fear anxiety and stigma to those who got infected with it. Healthcare workers were no exception in term of facing fear and anxiety (Mak et al., 2009)

After confirmation of the first coronavirus case in Pakistan on 26 February 2020, the government sealed its border with Iran, however, this ban could not be maintained for a long time because thousands of Pakistani pilgrims were stranded on the Pak-Iran border (Badshah et al., 2020). The government was left with no option except to open the border and establish quarantine centres at Taftan, a bordering city of Baluchistan, Pakistan. Government-appointed healthcare workers in the said quarantine centre were not provided with proper PPE (Zheng et al., 2020). Considering the situation in Quetta, healthcare workers serving in these centres without PPEs demanded medical gear, and baton-wielding police beat them, arresting them and putting them behind bars (Dawn, 2020).

With the exponential growth of coronavirus pandemic, the government established quarantine centres where suspected cases of the coronavirus were placed for two weeks. Healthcare workers were appointed for care and treatment of suspected cases in these quarantine centres. The government did not allocate ample resources for facilitation in quarantine centres, that is why there was an acute shortage of much-needed services in these centres such as food, separate washrooms, isolated beds, and necessary medicines. Numerous incidents were reported when the quarantined person or their attendants attacked 
healthcare workers, leaving them injured. A Karachi based doctor dealing with infectious diseases expressed her fear in these words: "If we refuse, based on their history, they turn around and get angry, and some even get downright abusive" (Dawn, 2020).

During the coronavirus pandemic, hospitals were flooded with confirmed as well as suspected coronavirus cases, some of them were symptomatic and others asymptomatic, but healthcare workers have to work in close proximity and were barely protected from deadly viruses. Furthermore, there was notable unpreparedness of the government for combating the novel virus without PPEs. It is worth mentioning that healthcare workers serving as front line forces were not given proper orientation and training about handling coronavirus patients (Xiang et al., 2020). Healthcare workers as the frontline force to fight against COVID-19 are exposed to coronavirus infection. Research studies show that healthcare workers infected with coronavirus were up to $20 \%$ of the infected population. Major reasons behind contraction of healthcare workers with coronavirus include lack of scientific knowledge about infection, unavailability of PPEs, and lack of testing and diagnostic facilities (Ali et al., 2020).

\section{Methodology}

The current study aimed at exploring various factors which created hindrances for healthcare workers while performing their duties during the coronavirus pandemic. The study is based on both primary and secondary data. For the comprehension of the health workers' condition during coronavirus pandemic, the study includes both doctors and nurses for data collection. Both doctors and nurses played a central role in medical settings and are serving as the frontline force during the coronavirus pandemic. We conducted in-depth qualitative interviews to study the impacts of the coronavirus pandemic on the personal and professional lives of healthcare workers, especially performing their duties under life-threatening conditions. We employed content analysis method to bring forward situation of these healthcare workers.
We interviewed 30 healthcare workers (15 doctors and 15 nurses) through telephone, Whats app and Zoom. The interviews were conducted in both Urdu and English languages, verbatim was later translated and transcribed into English for further analysis. For understanding the state of affairs, it was essential to study both categories of healthcare workers (serving in government hospitals) who are directly dealing with coronavirus cases and those serving in general wards. For ensuring confidentiality and privacy of study participants, they were given code names comprising of alphabets and numeral wherein category $A$ and $B$ representing doctors and nurses, respectively. The secondary data was based on online journal articles, daily newspapers, government reports and official websites. The findings are as follows:

\section{Findings}

The findings of the study have been divided into the following subcategories.

\section{Prevalence of anxiety and hysteria}

Just like the general population, healthcare workers were also suffering from anxiety and hysteria after learning about coronavirus from electronic and print media and social media. There was a prevalence of worry and anxiety on the part of healthcare workers because of immense fear on the part of rank and file. The government of Pakistan announced the closure of all educational institutions on 13 March 2020, however after ten days, the government had to impose stringent lockdown. Nevertheless, the duties of healthcare workers increased further, and they were to be present in the hospitals as a frontline force against COVID-19 pandemic.

Lockdown has brought more difficulties for us, we have to reach duty point through thick and thin despite being fearful of contracting the coronavirus, we cannot sit at home like ordinary people (Participants B3, interview 2 August 2020).

As the coronavirus pandemic was speedily spreading at an international level, there was an increase in anxiety and hysteria of getting infected and dying of this novel virus. The infection pattern of coronavirus is so fast that 
once you are out of home, there is stress of getting infected.

Every day, we left our home for hospital, there was huge amount of anxiety that either I would be back without getting infected with this deadly virus (Participant $A 2$, interview 2 August 2020).

\section{Worries about family}

During the COVID-19 pandemic, healthcare workers are more worried about their families than their own selves. The fear of contracting coronavirus from asymptomatic carriers, and then meeting with family members back at home was intimidating.

We healthcare workers are more panic and suffering from hysteria because we see sufferings and complications of coronavirus patients. Imagining our family members in such severe pain and trouble makes us deeply fearful and intimidating (Participant A5, interview 5 August 2020).

The healthcare workers having elderly parents are more worried about them because coronavirus is more dangerous for the elderly already having some co-morbidities. Likewise, parents of healthcare workers were also deeply stressed because of the deadly coronavirus.

Those among us who have babies are double-minded about continuing job during this pandemic; we are more concerned and careful about our babies than a job. Family and kids are, of course more important than a job (Participant A1, interview 31 July 2020)

Healthcare workers serving either in isolation wards or general wards were restricting their interaction with family members because of fear of being asymptomatic carriers of coronavirus.

After returning from the hospital, I do not meet with my parents and siblings, who knows that I am bringing this virus. I always use backdoor for entering into the home and living in self-imposed isolation just for the safety of my family members (Participant B9, interview 30 July 2020).
There was profound fear on the part of healthcare workers of bringing coronavirus to their homes and family members succumbing to this infection. A fair number of healthcare workers preferred to stay in hostels after duty hours instead of coming home.

Thoughts of infecting any family member from coronavirus always shivered me and feeling of guilt if my family had to pay this price of having a healthcare worker at home always left me in deep anxiety (Participant A7, interview 2 August 2020).

\section{Lack of proper training for preparedness and safety}

Based on surface information propagated by international agencies, WHO about the coronavirus pandemic were floating in electronic, print, and social media, everyone was aware of the cause, infection pattern, and its deadly implications. However, healthcare workers who had to be directly exposed to coronavirus patients needed proper orientation and training about the treatment of coronavirus patients and keeping self-protection from this deadly virus. The representative of the Asian Development Bank, while signing a contract agreement with the government of Pakistan for training healthcare workers, emphasised its need and importance in these words:

As the COVID-19 pandemic poses a significant healthcare challenge to Pakistani people and government, the training programme is led by the Health Services Academy will help boost the critical care system's efficiency and the capacity of the healthcare workers in responding to the current emergency situation and future critical care needs (Gulf News, 2020).

I was given neither orientation nor training about how to protect myself while dealing with a range of patients during coronavirus outbreak. Our entire knowledge about coronavirus pandemic came from mass media and informal discussion with colleagues and seniors (Participant B10, interview 28 July 2020). 
Lack of proper training of healthcare workers for preparedness and safety added to the stress and anxiety on their part, and they were hesitant and fearful about examining and treating patients.

I wish that there are neither patients in the hospitals nor I would be at risk of contracting coronavirus, we are being denied leaves these days because of influx of coronavirus patients (Participant A6, interview 3 August 2020).

\section{Lack of personal protection equipment}

After confirmation of the first coronavirus infected person in the Pakistan, there was distress on the part of rank and file about getting infected from this deadly virus. However, government officials made repeated claims that the healthcare system of the country is ready to respond to the challenges posed by this novel pandemic. However, the situation on the ground was different from this claim. Healthcare workers were not given proper PPEs for their own safety and protection even when there were thousands of confirmed coronavirus cases in the country, and there was a rapid increase in it. As stated by a doctor appointed in a quarantine centre "Some of us didn't even have basics like N-95 masks" (Arab News, 2020). It is worth mentioning that after some specific period, healthcare workers serving in the quarantine centres or isolation wards were supplied new safety kits. However, healthcare workers serving in the general wards were given only surgical masks, not face sheets, gowns, goggles, gloves, or hand sanitiser.

I am serving in the gynaecological ward but have not been given PPE as advised by the national ministry of health and WHO, I am given one surgical mask per month, I have to sanitise it again and again for making it useable for such a long time (Participant A4, interview 6 August 2020).

Healthcare workers were making local and selfsupported arrangements for their safety against coronavirus pandemic because of a lack of such provisions from hospital administration.

A junior doctor or nurse can afford to buy mask or hand sanitiser and ordinary gloves, but the complete kit is costly and cannot buy by our own self. Hospital administration should take such steps for mitigating risk factor and ensuring safety to its employees (B8, interview 25 July 2020).

\section{Non-compliance with SOPs by patients and their attendants}

Patients and their attendants while visiting hospitals did not comply with safety measures such as social distancing, use of face mask, and hand sanitising. There are many examples when wearing a mask or observing social distance was criticised by patients and their attendants.

We are not carrying coronavirus, do not think us contagious (Participant A13, interview 4 August 2020).

Some of the patients and their attendants were literally not aware of social distancing and face masks, however many of them knowingly did not adopt safety measures because of the belief that death has been pre-destined, and its time cannot be changed through any safety measure.

When time, place and cause of death is unchangeable, then why there is a need to be so fearful? Sometimes, even colleagues say you want to be immortal? I do not care because I would die at my pre-destined time (Participant B6, interview 26 July 2020).

While being in the hospital, it was not possible to maintain complete social distancing because many in the surroundings were not concerned about it.

We have to face threats and abusive language if we insist on compliance with coronavirus SOPs (Participant B12, interview 5 August 2020).

\section{Adopting safety measures in hot and humid weather}

Wearing complete safety kit was difficult in the hot and humid weather conditions of Pakistan in the summer season, when mercury fluctuates between $40^{\circ} \mathrm{C}-50^{\circ} \mathrm{C}$ in the months of June and July. 
It was difficult to breathe in three layered facemasks and face sheet that too in the isolation ward without air conditioners. Immediately after wearing this dress, one would be sweating from top to toe (Participant A10, interview 30 July 2020).

In ordinary circumstances, healthcare workers would wear simple masks and hand gloves while serving in the hospital ward. However, staying inside isolation wards and dealing with coronavirus confirmed cases was like seeing death closely, so there was no other option except wearing a full safety kit including face sheet, facemask, medical gown, goggles and long shoes.

When I wear full safety kit before entering isolation ward, I just start counting when I would be putting it off. It was quite risky to eat or drink anything before putting off that kit, taking bath and wearing other dress (Participant B11, interview 3 August 2020).

Healthcare workers serving in coronavirus wards had to tighten face masks around their faces which was a painful experience in itself. It was not possible to touch one's own face even you were feeling itchy.

It is silent enemy and we do not know how and when it would attack, having this deep fear in mind, we bear pain of adopting additional safety measures for keeping ourselves protected from this novel disease (Participant A3, interview 25 July 2020).

\section{The higher ratio of mortality among coronavirus patients on ventilators}

There was unusual high mortality rate of those coronavirus patients who were put on ventilators. Most of such patients were aged and having co-morbidities and when they were critical, it was likely to confirmation of their death. This situation added to the stress of healthcare workers and they doubted that either we are doing enough to save our patients.

Coronavirus patients who become critical and shifted on ventilators were hardly back. This experience has badly shaken the courage and confidence of the healthcare workers serving in the isolation wards because, in ordinary circumstances, the recovery rate is much higher as compared to during the coronavirus pandemic (Participant A9, interview 1 August 2020).

I just feel that we are doing nothing for the patients; that is why everyone on the ventilator dies. At times, we also question ourselves that either we are competent enough or trained well for taking care of such critical patients (Participant A13, 4 August 2020).

In the normal situation, only a minor percentage of patients die while the rest of them recover which serves as a mean of motivation and more energy for doctors for serving passionately, however, the higher death ratio of patients discouraged healthcare workers serving in isolation wards and leaving them disappointed and demotivated.

One day you see a patient walking, talking and eating and next day come to know that s/he has expired, what an emotional setback which leaves one broken and shattered (Participant A1, interview 31 July 2020).

Based on this experience, some healthcare workers also advised their friends and family not to take critical coronavirus patients to hospitals, instead recommended to keep such patients at home and take care by themselves.

\section{Emotional breakdown of coronavirus patients in isolation wards}

The novel coronavirus spreads through airborne droplets from the infected person, that is why coronavirus suspected, and confirmed cases were kept at quarantine centres and isolation wards respectively. Due to its fast transmission mode from one person to another and survival of coronavirus on different surfaces ranging from several hours to several days, each and every one was worrisome. At hospital, attendants of suspected and confirmed cases were not allowed to attend and them in either in quarantine centres or isolation wards, that is 
why the vast majority of suspected and confirmed coronavirus cases were emotionally down with little to no will power to resist and survive from coronavirus. There was no one with suspected and confirmed coronavirus cases for talking and keeping them strengthened and motivated.

Ironically, most of the patients coming to isolation wards are elderly, having comorbidities and unable to use information technology for talking to their near and dear ones, this pushes them into deep stress and emotional breakdown (Participant A15, interview 5 August 2020).

Some of the patients begged healthcare workers for making them talk to their family members through telephone. They just wanted to talk to their family members before dying. In the given situation, healthcare workers also talk to patients for solacing them and strengthening their will power to defeat coronavirus. This emotionally loaded situation profoundly influenced healthcare workers and their mental health which halted their performance during duty.

\section{Discussion}

The coronavirus pandemic has badly affected each and everyone across the globe, and healthcare workers are one of the most suffering communities as are serving as the frontline force for fighting against this deadliest virus. While examining and treating symptomatic and asymptomatic patients, healthcare workers contracted coronavirus and many of them succumbed to this pandemic.

Pakistan as a country allocates poor budget for healthcare system, that is why generally majority of population especially the poor are unable to access and avail healthcare services. The coronavirus pandemic has exposed the healthcare system of developed countries like the USA, the UK, and other European countries which failed to respond and cater to all the patients' needs. In this scenario, developing countries like Pakistan were ill-prepared to meet such gigantic challenges posed by the novel coronavirus. The doctor-patient ratio in Pakistan is already very poor: one qualified doctor for 963 persons and one hospital bed for 1608 persons (Government of Pakistan, 2018-19), and the coronavirus pandemic has further badly exposed its weaknesses. Healthcare workers including doctors, nurses, and paramedical staff were the front-line force for responding to this pandemic, however, in the case of Pakistan, the government did not take adequate and timely measures to equip them for serving at the healthcare centres properly. Both, government authorities and the masses were displaying a see what may come attitude towards the pandemic and assumed that novel coronavirus would not harm them as it did in several other countries like USA, France, Brazil, Italy and many more.

Healthcare workers were under a moral obligation to serve people under whatever risks prevail; that is why they were found as the frontline force during COVID-19. However, there are several essential factors which adversely affected their performance, such as lack of proper safety kits, concerns and worries about family members, and fears of contracting coronavirus despite taking strict safety measures. A cardiologist serving in a quarantine centre expressed his passion in these words: "As doctors, I think we are already mentally prepared to fight this war with whatever little resources we have" (Arab News, 2020). In some cases, healthcare workers were also overloaded, and sleep-deprived because of non-stop long duty hours which affected the quality of their performance.

\section{Conclusion}

This study aimed at examining the factors affecting the performance of healthcare workers during COVID-19 in Pakistan. The coronavirus pandemic has created stress and hysteria for each and every person around the globe, healthcare workers being the frontline force are more affected because of their direct exposure to coronavirus patients. Just like in other countries, in Pakistan too, healthcare workers are serving during the coronavirus pandemic in quarantine centres, isolation and general wards, however, they are not adequately equipped and trained to serve during this challenging time. If 
healthcare workers were given needed resources and training, they would have performed their duties in a better way. The lack of PPEs, overloading of work, and worries about contracting family members with coronavirus adversely affected their performance.

\section{References}

Ali, S., Noreen, S., Farooq, I., Bugshan, A., \& Vohra, F. (2020). Risk Assessment of Healthcare Workers at the Frontline against COVID-

19. Pakistan Journal of Medical

Sciences, 36(COVID19-S4). 99-103.

Arab News (2020, 12 April). Over 100 Healthcare Workers Infected with Covid-19 in Pakistan. Available at:

https://www.arabnews.pk/node/1657141/pakis $\tan$

Badshah, S. L., Ullah, A., Badshah, S. H., \& Ahmad, I. (2020). Spread of Novel Coronavirus by Returning Pilgrims from Iran to Pakistan. Journal of Travel Medicine, 27(3), 1-3, https://doi.org/10.1093/jtm/taaa044.

Dawn, (2020, 14 April). Pakistan's dilapidated health system bent double with COVID-19 scare Available at:

https://www.dawn.com/news/1542163

Dawn (2020, 7 April). Police baton-charge, arrest young doctors in Quetta during protest against lack of PPEs. Available at::

https://www.dawn.com/news/1546921.

Deshwal, V. K., (2020). COVID 19: A Comparative Study of Asian, European, American continent. International Journal of Scientific Research and Engineering Development, 3(2), 436-440.

Emro, W H O. (2019). WHO extends support to Pakistan as it confirms its first two cases of COVID-19 (Issue March). Available at:http://www.emro.who.int/pak/pakistannews/who-extends-support-to-pakistan-as-itconfirms-its-first-two-cases-of-covid-19.html

Government of Pakistan (2018-19). Pakistan Economic Survey, Ministry of Finance. Available at: http://www.finance.gov.pk/survey/chapters_16 /11_Health.pdf.

Government of Pakistan (2018-19). Pakistan Economic Survey, Ministry of Finance. Available at:

http://www.finance.gov.pk/survey/chapters_16 /11_Health.pdf.

Government of Pakistan (2019). Ministry of National Health Services Regulations and Coordination. Available at:

http://www.nhsrc.gov.pk/Detail/ZmM4OGZiMT UtY2RkNy00OWQ1LWE5NTgtZTQ3NWIzODU0 MDgy

Government of Pakistan (2018-19). Pakistan Economic Survey. Available at:

http://www.finance.gov.pk/survey/chapters_19 /11-Health\%20and\%20Nutrition.pdf

Gulf News (2020, 2 July). COVID-19: 4,500

Pakistan healthcare workers to get training.

Available at:

https://gulfnews.com/world/asia/pakistan/covi d-19-4500-pakistan-healthcare-workers-to-gettraining-1.72372016.

Khan, M. I. (2020). Coronavirus: Why Pakistan's doctors are so angry. $B B C$ News. Available at: https://www.bbc.com/news/world-asia52243901

Khalid, K., Abbasi, A., N., (2018). Challenges Faced by Pakistani Healthcare System:

Clinician's Perspective. Journal of the College of Physicians and Surgeons Pakistan, 28 (12), 899901.

Khan, M. M., \& Van den Heuvel, W. (2007). The impact of political context upon the health policy process in Pakistan. Public Health, 121(4), 278-286.

https://doi.org/10.1016/j.puhe.2006.09.015

Koo, J. R., Cook, A. R., Park, M., Sun, Y., Sun, H., Lim, J. T., \& Dickens, B. L. (2020). Interventions to Mitigate Early Spread of SARS-CoV-2 in Singapore: A Modelling Study. The Lancet Infectious Diseases. 20(6), 678-688.

Kurji, Z., Premani, Z. S., \& Mithani, Y. (2016). Analysis Of The Health Care System Of Pakistan: Lessons Learnt And Way Forward. Journal of 
Ayub Medical College, Abbottabad. 28(3), 601604.

Mak, I. W. C., Chu, C. M., Pan, P. C., Yiu, M. G. C., \& Chan, V. L. (2009). Long-term psychiatric morbidities among SARS survivors. General Hospital Psychiatry, 31(4), 318-326.

Rosenbaum, L. (2020). Facing Covid-19 in Italyethics, logistics, and therapeutics on the epidemic's front line. New England Journal of Medicine, 382(20), 1873-1875.

Salman, M., Mustafa, Z. U., Khan, T. M., Shehzadi, N., \& Hussain, K. (2020). How prepared was Pakistan for the COVID-19 outbreak?. Disaster Medicine and Public Health Preparedness, 1-2.

Saqlain, M., Munir, M. M., Ahmed, A., Tahir, A. H., \& Kamran, S. (2020). Is Pakistan prepared to tackle the coronavirus epidemic?. Drugs \& Therapy Perspectives, 1-2.

Sherin, A. (2020). Coronavirus Disease 2019 (COVID-19): A Challenge of Protecting the General Population and Health-Care Workers. Khyber Medical University Journal, 12(1), 4-5.

Tribune (2020). Govt urges social distancing as Pakistan celebrates Eidul Fitr; Covid-19 tally crosses 55,000 (20 May, 2020). Available at: https://tribune.com.pk/story/2228302/liveeidul-fitr-celebrated-across-pakistan-covid-19tally-reaches-54601

Waris, A., Atta, U. K., Ali, M., Asmat, A., \& Baset, A. (2020). COVID-19 outbreak: current scenario of Pakistan. New Microbes and New Infections, 35(20), 100681.

https://doi.org/10.1016/j.nmni.2020.100681.

World Health Organization (2020). Advice for Health Workers. Available at:

https://www.who.int/westernpacific/news/mul timedia/infographics/advice-for-healthworkers.

Xiang, Y. T., Jin, Y., Wang, Y., Zhang, Q., Zhang, L., \& Cheung, T. (2020). Tribute to Health Workers in China: A Group of Respectable Population during the Outbreak of the COVID-
19. International journal of biological sciences, 16(10), 1739.

Zheng, W. (2020). Mental health and a novel coronavirus (2019-nCoV) in China. Journal of affective disorders, 269, 201.

Zia, K., \& Farooq, U. (2020). COVID-19 Outbreak in Pakistan: Model-Driven Impact Analysis and Guidelines. ArXiv Preprint ArXiv. http://arxiv.org/abs/2004.00056. 1-14

\section{Conflict of Interest}

No conflict of interest

\section{Acknowledgements}

The authors acknowledge Professor Venkat Pulla's mentorship throughout this study, we also pay thanks to anonymous reviewers for giving their valuable comments for making this manuscript an acceptable paper.

\section{About the Author}

Dr. Muhammad Jafar received his master's in social work from University of the Punjab, Lahore in 2003. Currently he is serving as lecturer at Department of Social Work, The Islamia University of Bahawalpur. He earned his PhD from Universiti Sains Malaysia in 2017. He has published in peer reviewed research journal at national and international level. His research interests include social protection, social work education and curriculum.

Dr. Aisha Shoukat is currently serving as assistant professor at department of social work, The Islamia University of Bahawalpur. She got her PhD in social work from University of Peshawar in 2016. During PhD, she was awarded funding from HEC Pakistan under its International Research Support Initiative Program and went to The University of York, UK as research fellow. Her research interests include social issues of women, social work and social institutions, social development.

\section{Author Contribution Statement}

The first author conceptualised the paper and contributed in drafting introduction and literature review. The second author prepared interview guide, collected and transcribed the 
data and organised it into sub themes. Then both authors drafted discussion and conclusion and second author reviewed the complete manuscript before submission. 